\title{
EDITORIAL
}

\section{Do I have a conflict of interest? Yes}

\author{
Djillali Annane ${ }^{1 *}$ and Bernard Charpentier ${ }^{2}$
}

๑ 2018 Springer-Verlag GmbH Germany, part of Springer Nature and ESICM

Conflict of interest is part of the daily life of human beings since ever. It is a permanent concern in the practice of law, and for instance, an attorney cannot represent a third party whom interests are opposed to those of his/her client. In the field of health science, in the early sixties, the issue of scientific people taking advantages from a government appointment was already a matter of debate [1]. In the past decade, in the number of scientific publications addressing the issue of conflict of interest in medicine increased remarkably (from about 600 in 2008 to roughly 30,000 in 2017) [2]. The observation that a majority of US academic institutions have no or insufficient policies covering the relationship between industries and members of institutional review boards [3] raised public concern [4], and may have contributed to increasing interest for this topic in the medical literature.

A conflict of interest can be defined as any situation in which a decision (or an action) taken by a professional in his/her duty (e.g., medical doctor prescribing a drug to his/her patient, or an investigator recruiting a research participant) is influenced by his/her relationship with a third party, providing directly or indirectly to the professional and/or to the third party, personal benefits whether financial or not [5]. Of note, the presence of a conflict of interest is not synonymous of malpractice or professional misconduct. Sometimes there are no consequences on the professional's duty, and possibly sometimes they may be positive consequences for the patient. For example, a cancer patient may benefit from an innovative intervention before the drug is marketed,

\footnotetext{
${ }^{*}$ Correspondence: Djillali.annane@aphp.fr

${ }^{1}$ Department of Intensive care medicine, School of health science

Simone Veil, Raymond Poincaré University Hospital (APHP), University of Versailles SQY University Paris Saclay, 104 boulevard Raymond Poincaré, 92380 Garches, France

Full author information is available at the end of the article
}

For contrasting viewpoints, please go to https://doi.org/10.1007/s00134018-5298-2 and https://doi.org/10.1007/s00134-018-5299-1. by being recruited to participate to an industry driven trial which principal investigator is the patient's physician. Nevertheless, conflict of interest may also be source of wrongdoing, as illustrated by the so-called "Benfluorex (MEDIATOR)-case" in France [6]. The "MEDIATOR" trial is still on-going. So far, judicial investigations have evidenced that medical doctors acting as experts for health authorities, and politicians, had strong links with and drew individual benefits from the pharmaceutical industry owning the marketing authorization for this drug. As a consequence, there was an unacceptably long delay in drug withdrawal from the market and unduly prolonged exposures of thousands of patients to serious adverse events with some fatalities. The decisions and actions that one is taking in his/her professional occupation are necessarily based on his/her own experience, values and knowledge which always rely on external influence. They are also driven by some individual interests for the professional, such as gaining more experience and skills, or better reputation among peers or lay public. No one legitimately conducts his/her duty without expectation of some personal benefit. No one deliberately behaves badly. In many cases, the professional may be unaware of the potential conflict of interest. Sometimes, a professional albeit knowing his/her potential conflict of interest, would naively fail to recognize any risk of negative impact, such as malpractice in patient's care or misconduct of a scientific research. Nevertheless, someone may be intentionally shafted by a professional's duty. For example, a peer reviewer may provide excessively negative comments and recommendation to reject a scientific piece (e.g., scientific paper, grant application) because it goes the opposite way of the reviewer's previous publications, or it may compromise the reviewer's carrier, or because it is the work from a competitor [7].

Because potential conflict of interest exists for any decision/action taken by a professional, the risk of subsequent direct or indirect harms to people must be minimized. In the health sector, several countries have

\section{Springer}


Table 1 Kit tools for managing conflict of interest ${ }^{a}$

\begin{tabular}{|c|c|}
\hline Domain & Tools for institutions \\
\hline Education & $\begin{array}{l}\text { - Defined learning objectives } \\
\text { - Training materials (MOOC) } \\
\text { - Simulation-based training }\end{array}$ \\
\hline Prevention & $\begin{array}{l}\text { - Effective conflict-of-interest policy (regularly updated) } \\
\text { - Ethics board } \\
\text { - Ethics code of conduct } \\
\text { - Effective control and management program } \\
\text { - Established transparent severe sanctions for undisclosed conflict-of-interest } \\
\text { - Promotion of integrity } \\
\text { - Identification of "at risk" areas/situations } \\
\text { - Listing of situations and activities that are incompatibles with duty of institution's professionals } \\
\text { - Providing examples of personal interest that may generate conflict-of-interest issues } \\
\text { - Self-Questionnaires }\end{array}$ \\
\hline $\begin{array}{l}\text { Evaluating/Solving/ } \\
\text { Enforcing/Communicating }\end{array}$ & $\begin{array}{l}\text { - Disclosure at time of appointment or promotion } \\
\text { - Defined regular intervals to update disclosures } \\
\text { - Defined what should be public (open access) and what may remain for internal use } \\
\text { - Independent review of self-declaration } \\
\text { - Defined strategies for positive resolution of conflict-of-interest (e.g. recusal for involvement in decision-making-process; } \\
\text { reassignment of duties; restriction of duties; resignation from conflicting private activities or from public services) } \\
\text { - Registry for all declaration of conflict-of-interest, with full or partial open access } \\
\text { - Increase awareness and compliance of professionals by setting up speaking groups, sending reminders, providing guid- } \\
\text { ance and assistance } \\
\text { - Procedures to deal with allegation of individual's violation to ethics code and disclosure } \\
\text { - Executing sanctions in cases of violation of institution's policy } \\
\text { - Public release of Institution's conflict-of-interest policy and of executed sanctions }\end{array}$ \\
\hline
\end{tabular}

${ }^{a}$ Adapted from reference 11

regulated by law the financial relationship between health care professionals and industries. The Sunshine Act was adopted in the US in 2010 and mandates that any direct or indirect payment of 10USD or more to healthcare provider by a private company must be publicly reported via the Open Payments website, as well as any ownership interest a physician or his relative may hold [8]. Following the "MEDIATOR" case, France adopted a similar law in 2011, with declaration of any interest of 10 euros or more, on the transparence.gouv.fr site supervised by the French Ministry for Social Affairs and Health [9]. Many member States of the European Union have now enacted similar laws [10]. There is no such straightforward definition for academic conflict of interest. It may be difficult to figure out all potential areas for academic conflict of interest, and what may be the ultimate direct or indirect benefit of a professional involved in academic issues related to another professional. Sometimes, the benefit could be academic promotion or promotion of a relative. It could be unfair scientific competition. For example, a peer reviewer may slow down the review process of a scientific paper or a grant application, to favour his/her own scientific work. The Organisation for Economic Co-operation and Development (OECD) has developed guidelines to help countries managing conflict of interest in the public services that obviously are relevant to the health sector [11]. Beyond national laws and OECD recommendations, the healthcare community has a major role in the management of financial or academic conflict of interest. Actions should be taken in three domains. First, education programs should be implemented in medical schools. Students should learn about conflict of interests and how to manage them in their future professional life. Physicians should maintain competencies with regard to this issue as a mandatory part of their continuous medical education programs. Second, every institution involved in the health sector, whether public or private, including regulatory agencies, public authorities, hospitals, universities, scientific societies, scientific journals, should have regularly updated own policies for prevention and early detection of conflict of interests including identification of areas at risk and kit tools (Table 1). These institutions should implement such regulations in the first place. Third, institutions should have an ethics board to independently assess every self-declared conflict of interest before they are made transparent through active communication. Ethics board should also propose beforehand, serious sanctions for intentionally undisclosed conflicts of interest, which may help preventing such misconduct. 


\section{Author details}

${ }^{1}$ Department of Intensive care medicine, School of health science Simone Veil, Raymond Poincaré University Hospital (APHP), University of Versailles SQY University Paris Saclay, 104 boulevard Raymond Poincaré, 92380 Garches, France. ${ }^{2}$ Deparment of Nephrology, Faculty of Medicine, Paris-South, Bicêtre University Hospital Kremlin-Bicêtre (APHP), University of Paris Saclay, rue du Général Leclercq, 94275 Kremlin-Bicêtre, France.

Received: 3 June 2018 Accepted: 20 June 2018

Published online: 20 August 2018

\section{References}

1. Anonymous.Conflict of Interest.Science (1962) 138(3543):865

2. https://www.ncbi.nlm.nih.gov/pubmed/?term=conflict+of+interest (accessed may 28th 2018)

3. Vogeli C, Koski G, Campbell EG (2009) Policies and management of conflicts of interest within medical research institutional review boards: results of a national study. Acad Med 84:488-494

4. McGreevey S. Policies regarding IRB members' industry relationships often lacking. https://www.eurekalert.org/pub_releases/2009-03/mghpri032309.php (accessed May 28th, 2018)
5. Thompson DF (1993) Understanding financial conflicts of interest. N Engl J Med 329:573-576

6. Chazan D. France pledges reform after diabetes drug scandal. BBC News Paris, 15 January 2011. http://www.bbc.com/news/world-europe-12200 506 (accessed May 28th, 2018)

7. https://www.enago.com/academy/avoiding-conflict-interest-in-peerreview/ (accessed June1st 2018)

8. Centers for Medicare and Medicaid Services (2013) medicare, medicaid, children's health insurance programs: transparency reports and reporting of physician ownership or investment interests. Fed Reg 78(27):9457-9528

9. https://www.legifrance.gouv.fr/eli/decret/2013/5/21/2013-414/jo/texte (accessed June 1st 2018)

10. Santos A. (2017) The Sun shines on Europe: transparency of financial relationships in the healthcare sector. Health Action International.http:// haiweb.org/wp-content/uploads/2017/03/Sunshine-Act.pdf (accessed June 1st 2017)

11. OECD guidelines and overview (2003) Managing conflict of interest in the public services. http://www.oecd.org/gov/ethics/48994419.pdf (accessed June 1st 2018) 